\title{
Racismo, trabalho e ociosidade no processo de abolição: o Brasil e o Império Português numa perspectiva global (1870-1888)
}

\author{
Racism, Labor and Idleness in the Abolition Process: Brazil and \\ the Portuguese Empire in a Global Perspective (1870-1888)
}

Paulo Cruz Terra ${ }^{\star 1}$

Resumo: O presente artigo pretende analisar como a perseguição à ociosidade foi um elemento-chave nas políticas de controle sobre o trabalho no contexto da abolição, bem como investigar como essa perseguição estava pautada pelo racismo ao atribuir aos negros uma ociosidade natural. Geralmente abordado para o período do pós-abolição, busca-se mostrar que esse é um processo anterior. Além disso, outra novidade consiste em se debater como as relações entre legislação, trabalho e raça no contexto da abolição não estiveram circunscritas unicamente ao Brasil, e, a partir de uma perspectiva da História Global do Trabalho, pretende-se refletir sobre as conexões e as comparações com o caso do Império Português, nas formulações sobre a África, ao longo do mesmo período.

Palavras-chave: Racismo; trabalho; ociosidade; História Global do Trabalho.
Abstract: This article analyses how the persecution of idleness was a crucial element in Abolition's labor control measures and investigates how that persecution was driven by racism, attributing natural idleness to black people. Generally addressed for the post-abolition period, the intention here is to show that it is an earlier process. The article also innovates by discussing how relations among legislation, labor and race, in the Abolition context, were not limited to Brazil and, in a Global Labor History perspective, reflects on the connections and comparisons with the case of the Portuguese Empire in its formulations about Africa over the same period.

Keywords: Racism; Labor; Idleness; Global Labor History.

\footnotetext{
* Universidade Federal Fluminense (UFF), Niterói, RJ, Brasil. pauloterra@gmail.com <https://orcid. org/0000-0002-0717-3399>
} 
Ao comentar a fala do trono proferida pela Princesa Isabel, em 3 de maio de 1888, que tratava da necessidade da extinção do elemento servil, ao mesmo tempo em que trazia a importância de aperfeiçoar a "nossa legislação repressiva da ociosidade", a folha diária Gazeta da Tarde indicava que parecia que o governo estava imbuído da "falsa ideia de que o liberto torna-se inimigo do trabalho e da ordem pública"2. Além de comentar que a experiência provava o contrário, indagava o jornal: "Quer o governo libertar os negros para metêlos na cadeia? Armar uma polícia rural, violenta e despótica ao serviço dos ex-senhores maus que não sabem se acomodar às novas condições de trabalho?" (Semana parlamentar, 1888, p. 1) . $^{3}$

As questões levantadas pela Gazeta da Tarde apontam os eixos do presente artigo, que pretende analisar como a perseguição à ociosidade foi um elemento-chave nas políticas de controle sobre o trabalho no contexto da abolição, bem como investigar como essa perseguição estava pautada pelo racismo ao atribuir aos negros uma ociosidade natural. Geralmente abordado para o período do pós-abolição ${ }^{4}$, busca-se mostrar que esse é um processo anterior.

Outra novidade consiste em debater como as relações entre legislação, trabalho e raça no contexto da abolição não estiveram circunscritas unicamente ao Brasil. Segundo Alain Youssef, a abolição da escravidão foi tratada na historiografia brasileira até recentemente unicamente dentro do escopo nacional (Youssef, 2019, p. 2). Esse é um ponto comum também à historiografia sobre a abolição no Império Português. A partir de uma perspectiva da História Global do Trabalho, pretende-se justamente refletir sobre as conexões e comparações entre o caso brasileiro e o do Império Português, nas formulações sobre a África, ao longo do mesmo período.

A acepção de História Global do Trabalho aqui utilizada está conectada às formulações de Marcel van der Linden no que diz respeito, por exemplo, ao questionamento do nacionalismo metodológico, focando assim nas conexões transnacionais ou transcontinentais, o que significa "colocar todos os processos históricos em um contexto maior, não importando quão geograficamente 'pequenos' sejam esses processos" (Linden, 2013). Atualmente existem muitas visões diferentes sobre o que é a História Global do Trabalho, assim como há um intenso debate sobre as suas possibilidades (Winn, 2012). O presente projeto se aproxima das perspectivas que pensam no global "por meio de uma ênfase no espaço e nas conexões que se estendem além das fronteiras cultu- 
rais", em vez de pensar no global como o mundo inteiro (De Vito, 2019). Nesse sentido, analisar como o racismo presente na legislação abolicionista circulou pelos espaços aqui abordados, e esteve diretamente relacionado ao controle sobre a força de trabalho, é uma possibilidade de fazer a História Global do Trabalho.

Além disso, o presente artigo se aproxima da História Global do Trabalho proposta por Linden ao explorar diferentes relações de trabalho, isto é, ao recusar uma abordagem tradicional que confunda a história do trabalho com a história do trabalho assalariado (Linden, 2013). Se a historiografia do trabalho produzida no Brasil tem avançado na investigação de formas de trabalho coercitivo no século $\mathrm{XIX}^{5}$, ainda são muito precários os esforços recentes de análise dos efeitos do racismo na história dos mundos de trabalho do país (Popinigis; Terra, 2019).

A primeira parte do artigo dedica-se a averiguar como, no contexto da abolição, se consolidou uma imagem de diferenciação racial que relacionava os negros a uma ociosidade atávica e, ao mesmo tempo, apontava para a necessidade de criação de medidas que reprimissem a vadiagem e regulassem os contratos de trabalho. A segunda parte explora justamente as tentativas, no Brasil e no Império Português, que foram concomitantes e relacionadas, de se responder a essas demandas através de leis e regulamentos. A partir dessa abordagem, objetiva-se contribuir para a análise do racismo no processo de transformação das relações de trabalho no Brasil e na África portuguesa, e para um olhar mais atento sobre a construção de formas coercitivas de trabalho nos espaços aqui abordados.

\section{OCIOSIDADE E TRABALHO FORÇADO}

Aprovada no Brasil em 28 de setembro de 1871, a legislação conhecida como "Lei do Ventre Livre" tinha como ponto principal libertar os filhos e as filhas das mulheres escravas que nascessem a partir da data da lei. Contudo, condicionava que essas crianças ficariam em poder, e sob a autoridade, dos senhores de suas mães até a idade de oito anos. Após esse período, o senhor poderia receber uma indenização, ou "utilizar-se dos serviços do menor até a idade de 21 anos completos" (Lei de 28 de setembro de 1871).

A lei possui muitos outros pontos, tendo alguns historiadores ressaltado 
a importância da garantia do direito dos escravizados de formar um pecúlio, e de obter a alforria caso tivessem os meios para indenizar o seu valor (Chalhoub, 1990). O que ainda não foi muito explorado é seu aspecto coercitivo em relação à vadiagem, exposto, por exemplo, na determinação de que os escravos libertados em virtude da lei ficariam "durante cinco anos sob a inspeção do Governo", e seriam "obrigados a contratar seus serviços sob pena de serem constrangidos, se viverem vadios, a trabalhar nos estabelecimentos públicos" (Lei de 28 de setembro de 1871) ${ }^{6}$. O constrangimento do trabalho, no entanto, cessaria se o liberto apresentasse um contrato de serviço.

Vigorava, na época da lei de 1871, o Código Criminal datado de 1830, que, no seu artigo 295, estipulava como vadia a pessoa que não tivesse uma ocupação honesta, "e útil, de que possa subsistir, depois de advertido pelo Juiz de Paz, não tendo renda suficiente". A pena era a prisão com trabalho por oito a vinte e quatro dias (Brasil, 1830).

A questão da obrigação e do constrangimento ao trabalho aparece em outra lei também de 1830, que dizia respeito ao regulamento do contrato de prestação de serviços. O dispositivo legal determinava que quem prestasse serviço só poderia negar-se a fazê-lo se restituísse os recebimentos adiantados, "descontados os serviços prestados, e pagando a metade do que mais ganharia, se cumprisse o contrato por inteiro" (Lei de 13 de setembro de 1830). Não cumprindo essa norma, que implicava na prática em que o trabalhador pagasse ao seu contratante, o Juiz constrangerá o "prestador dos serviços a cumprir o seu dever, castigando-o correcionalmente com prisão, e depois de três correções ineficazes, o condenará a trabalhar em prisão até indenizar a outra parte" (Lei de 13 de setembro de 1830).

Nos debates no Senado sobre a referida legislação, o Senador Vergueiro indagava sobre os recursos que havia para "fazer o homem trabalhar, e cumprir o contrato". Segundo o mesmo, a gente "que se aluga, ordinariamente não cumpre o que diz: vão-se embora; vão gastar o dinheiro que receberam”, daí a necessidade de sujeitá-los ao rigor das leis (Anais do Império..., Seção de 17 de junho de 1830).

Embora não estivesse limitada unicamente aos trabalhadores imigrantes, eram estes que estavam na mira da fala do Senador Vergueiro, o qual procurava garantir o retorno financeiro para empresários que, como ele, estavam envolvidos na vinda dos imigrantes (Cravo; Rodrigues; Godoy, 2020). A pró- 
pria lei em si foi editada por conta da fundação da Sociedade Promotora da Colonização Estrangeira (Alencastro, 1988, p. 36).

Uma outra lei de locação de serviços aprovada em 1837, e que dizia respeito exclusivamente aos estrangeiros, tornou ainda mais rígida a coerção aos trabalhadores que desejassem sair dos contratos. Nesse caso, se não pagassem seriam imediatamente presos e condenados "a trabalhar nas obras públicas por todo o tempo que for necessário, até satisfazer com o produto líquido de seus jornais tudo quanto dever ao locatário" (Lei de 11 de outubro de 1837). O que essas legislações indicam, segundo Télio Cravo et al., é a construção de um aparato que "restringia a mobilidade e demarcava as engrenagens coercitivas" em relação aos trabalhadores livres no Brasil. As referidas leis procuravam "canonizar as relações de dependência do trabalhador; impossibilitá-lo de se ausentar ou se evadir do trabalho; e, se necessário, condená-lo à prisão" (Cravo; Rodrigues; Godoy, 2020).

No contexto da primeira metade do século XIX, as leis que diziam respeito aos contratos de trabalho eram as mais voltadas diretamente para o controle da mobilidade da população livre. Apesar da existência da perseguição à vadiagem na legislação criminal brasileira, como comentado anteriormente, a preocupação da polícia nesse período, pelo menos no caso da Corte, estava mais direcionada à questão da mendicância, que no próprio Código Criminal estava aproximada à vadiagem (Holloway, 2008).

Mesmo existindo enquanto dispositivo legal, a perseguição à vadiagem é reeditada na lei de 1871, só que, nesse momento, especificamente para os libertos pela lei, como visto anteriormente. Sendo assim, é possível afirmar que é construído na letra da lei um sentido racializado de quem era o vadio, isto é, homens e mulheres de pele negra egressos do cativeiro. Por mais que a formulação sobre vadiagem no Código Criminal de 1830 e na Lei do Ventre do Livre se assemelhassem, no sentido de colocarem o trabalho como uma obrigação, a última, que incidia exclusivamente sobre os libertos, reforçava ainda mais as formas de controle, pois a esse trabalhador não bastaria somente apresentar uma ocupação, mas ele deveria mostrar-se empregado por alguém. Enfatizavase, portanto, a necessidade de que os trabalhadores negros libertos fossem submetidos a um patrão.

No que diz respeito ao processo de construção do liberto enquanto potencial vadio, é possível identificar que a Comissão responsável pela elaboração 
do projeto da Lei do Ventre Livre argumentou que a abolição imediata "corresponderia praticamente à erupção de um vulcão destruidor”. A justificativa é que seriam lançadas à liberdade massas que não foram nela educadas, e eram “incapazes de exercer as graves funções do cidadão”. O escravo prematuramente libertado,

faltando-lhe religião, zomba da consciência; faltando-lhe disciplina, zomba dos homens; faltando-lhe ensino, desconhece as vantagens da civilização; faltandolhe a coação ou incentivo, torna-se vagabundo; faltando-lhe o trabalho, rouba; faltando-lhe o receio; faltando-lhe a moralidade, arroja-se a todos os delitos (Diários da Câmara dos Deputados, Seção de 30 de junho de 1871).

Além de colocar que o liberto não estava preparado para a liberdade repentina, chegando a categorizá-la como um "presente de grego", a Comissão apontava que haveria a desorganização do trabalho, impactando diretamente a classe agrícola.

A necessidade de uma emancipação gradual tendo como justificativa a ociosidade inerente aos negros também circulava pelas páginas das folhas diárias da Corte do Império. Em uma publicação a pedido, do Diário do Rio de Janeiro de 16 de abril de 1871, assinada por "O lavrador", afirmava-se que "a liberdade plena, sem sujeição alguma, tem sido perniciosa", pois "o escravo não predisposto para uma rápida emancipação, entrega-se à ociosidade e aos vícios" (O elemento servil XI, 1871, p. 2). Já no Jornal do Commercio do dia 2 de julho de 1871, em uma seção semanal voltada a criticar o projeto de libertação do ventre, indicava-se que uma projeção do alto número de libertos que passaria a existir em 20 anos limitava as possibilidades de criá-los, "de educálos, de os policiar, de os obrigar ao trabalho". O vasto contingente imaginado iria "desenvolver em larga escala a ociosidade, a vagabundagem, o banditismo" (Emancipação: resumo da semana, 1871, p. 5).

No início de 1872, ao comentar os acontecimentos do ano anterior, o Jornal do Commercio afirmava que a Lei do Ventre Livre havia encetado um "escabroso e arriscado problema social" e demandava leis que pudessem ter real efeito. Uma primeira, no sentido de "obrigar e de sujeitar ao trabalho, à ocupação laboriosa em todos os municípios do interior os inúmeros proletários, ociosos e vadios", que formam "uma multidão de trabalhadores que se perdem na ociosidade da preguiça”. A outra medida seria voltada ao sistema 
de regulação dos contratos, que obrigasse ao trabalho os alforriados, os quais, em grande parte "corrompidos pelos vícios e pelas torpezas da escravidão esmolam e furtam em vez de trabalhar para viver, e danificam a sociedade que cooperou para a sua regeneração" (Brasil, 1872, p. 2). A coerção à vadiagem prevista na lei de 1871 parecia ainda não ser suficiente para obrigar os libertos - degenerados, na opinião da folha diária - a trabalhar?

A ideia de uma transição paulatina e suave entre escravidão e liberdade tinha inspiração no que a Comissão responsável pela elaboração da lei de 1871 considerava como sendo as experiências positivas de abolição gradual "na Inglaterra, na Suécia, na Dinamarca, nas repúblicas de língua espanhola, em Portugal” (Diários da Câmara dos Deputados, Seção de 30 de junho de 1871).

A inspiração internacional não foi à toa. Como afirmou a Comissão, outros países já haviam adotado a abolição gradual. No caso do Império Português, um decreto de 1858 determinou a abolição nas colônias em 20 anos. Em 1869, outro decreto estabeleceu que os escravos passariam à condição de libertos com a obrigação de terem que trabalhar para seus senhores até 1878 .

Assim como no Brasil, era recorrente se encontrar a associação entre os negros e a ociosidade presente, por exemplo, nos debates parlamentares portugueses. Na sessão do dia 12 de abril de 1864, o deputado Pinto de Magalhães, ao discutir a introdução do trabalho forçado como substituto da escravidão, apontava que o trabalho era uma necessidade para a África, pois sem ele "não há riqueza nem felicidade, há vícios e ociosidade". Diante da constatação de que o "preto não quer trabalhar", o deputado indicava que Portugal deveria introduzir o trabalho forçado, mesmo caminho adotado por outras nações, como Espanha, Inglaterra e França, que, apesar de pregarem em tese o trabalho livre, na prática forçavam o trabalho das populações das colônias (Câmara dos Senhores Deputados..., Seção de 12 de abril de 1864).

O Ministro da Marinha Mendes Leal, ao comentar a fala do referido deputado, afirmou que o trabalho tinha o poder de civilizar a África, e que o continente passava por um processo que já havia ocorrido na sociedade europeia, que consistia em uma "transição natural": a passagem da "escravidão para a servidão, isto é, do trabalho escravo, ou a pena, para o trabalho obrigatório, ou o dever". O ministro prossegue citando Geoffroy Saint-Hilaire, "um propugnador da diferença das raças, um investigador sem suspeita do negrófilo"8. Segundo Mendes Leal, Saint-Hilaire propunha para o "ínfimo africano" 
uma tutela paternal, e para o ministro essa tutela produziria o trabalho obrigatório e admitia a servidão (Câmara dos Senhores Deputados..., Seção de 12 de abril de 1864).

Às formulações de Mendes Leal se aproximavam as do também português João Pedro de Oliveira Martins. Este, segundo Ernesto Zamparoni, era adepto da Antropologia Física predominante no final do século XIX (Zamparoni, 2012, p. 50). Na obra O Brasil e as colónias portuguesas, publicada em 1880, Oliveira Martins apontava que existiam diversos documentos que mostravam o negro "como um tipo antropologicamente inferior, não raro próximo do antropoide, e bem pouco digno do nome homem”. Semelhante à concepção de Mendes Leal, o negro, para Oliveira Martins, dava a impressão de ser uma criança adulta, e mesmo que tivesse qualidades infantis, como a mobilidade e a agudeza, essas não "se transformaram em faculdades superiores". A disciplina do trabalho era a forma de tirar esse ser inferior do "estado de indolência e ociosidade", pois não "abandona a liberdade e a ociosidade, para ele felizes condições da vida selvagem, pelo trabalho, fixo, ordinário, constante, que é a dura condição da vida civilizada" (Martins, 1880, p. 212).

A associação dos africanos a uma ociosidade atávica também circulava em Portugal por meio de opúsculos que debatiam o fim da escravidão, como o publicado por Alfredo de Oliveira Pires em 1874. Ele expôs que a obrigação do trabalho para os pretos, "uma raça recém-saída da escravidão e do estado quase selvagem", só poderia ser imposta pela lei, sendo indispensável compeli-los a respeitá-la. Caso isso não fosse feito, veríamos "o preto convertido em vadio, porque nem a consciência dos deveres sociais, nem as suas próprias exigências o levarão ao exercício do trabalho" (Pires, 1874, p. 34). Como solução propunha a criação de um regulamento sobre os contratos de trabalho com os africanos, e ainda

providências policiais para reprimir a vadiagem, a fim de que a indolência natural dos pretos os não leve a abandonar todos os trabalhos e a entregar as colônias à crise proveniente da falta de braços, expondo ao mesmo tempo ao perigo de um numeroso bando de vadios, sem educação, nem cultura e fáceis de cair em todos os vícios (Pires, 1874, p. 15).

Felix Meyer, em opúsculo também publicado em 1874, apontou que o estado selvagem em que ainda se conservavam "os povos indígenas de Angola, 
oferece a prova mais evidente", para ele, do fato de que o "negro neste seu país natal jamais soube sujeitar-se voluntariamente a um trabalho regular". $\mathrm{O}$ atraso "intelectual e moral" que essa população apresentaria não poderia, no entanto, ser atribuído a "uma inferioridade inata e própria da raça", como exposto pelo ministro Mendes Leal, baseado nas ideias de Geoffroy Saint-Hilaire. Para Meyer, a

influência enervante do clima e a fertilidade espontânea do solo, que lhes facultam o satisfazer as suas poucas necessidades sem precisarem de sujeitar-se a um trabalho regular são as causas permanentes, que permitiram desde os tempos primordiais, e permitem ainda hoje ao negro de Angola de entregar-se ao ócio, que para ele é a condição do seu bem-estar (Meyer, 1874, pp. 8-9).

O mesmo autor cita experiências nos Estados Unidos e nas Antilhas Britânicas para exemplificar casos em que os negros fora da África, assim como no próprio continente, não se sujeitavam ao trabalho. A plena e imediata emancipação dos negros, segundo Meyer, "aniquilaria completamente as importantes colônias agrícolas fundadas pelos europeus", e por isso era necessário constranger e obrigar os negros a trabalhar (Meyer, 1874, p. 15).

Sá da Bandeira, importante abolicionista português e formulador de várias leis concernentes ao fim da escravidão no Império Português ${ }^{9}$, em obra de 1873, rebateu algumas das associações correntes de que os negros seriam necessariamente ociosos e repeliriam o trabalho. A sua argumentação era de que os negros recusariam o trabalho quando não tinham o salário pago, ou esse era insuficiente, ou ainda quando eram maltratados. No entanto, ele afirmava que era necessário que o governo conduzisse os negros libertos "a adotarem alguns dos usos da gente civilizada, tais como a frequência das escolas e o vestuário”. Dessa forma, "o desejo de possuírem os objetos precisos, lhes criará a necessidade de trabalharem para o satisfazer" (Bandeira, 1873, p. 73).

Sá da Bandeira apontou, ainda, que era essencial "definir bem claramente a aplicação" que, nas colônias, "deve ser dada à palavra vadio; atentando a que as mulheres negras são quem, em geral, se ocupa [sic] da agricultura e de outros misteres". Reafirmava, assim, a importância, para que não se repetisse o ocorrido em Angola em 1840, que "incluiu na classe de vadios a maior parte dos negros livres daquela província”. Dessa forma, o autor alertava para o que considerava ser uma crucial divisão de gênero do trabalho na África, a qual certa- 
mente impactaria na criminalização da vadiagem nesse espaço. Ele também indicava a importância de que a pena de trabalho fosse cumprida em instituições do Estado, proibindo que os serviços dos vadios fossem prestados a particulares, "para evitar especulações e grandes abusos" (Bandeira, 1873, p. 74).

As representações sobre os negros libertos que circulavam entre o Brasil e o Império Português não se restringiam unicamente a esses espaços. No processo de abolição inglês que data do início da década de 1830, mencionado pela Comissão responsável pela elaboração da lei de 1871 no Brasil, debateu-se também a ideia de que o caráter dos libertos, intelectualmente inferiores, e a falta de incentivos para trabalhar fariam com que a repentina e completa emancipação os levasse à indolência bárbara. Segundo Thomas Holt, o objetivo do governo era, portanto, encontrar um sistema que pudesse retirar as comunidades das Índias Ocidentais do barbarismo. O projeto vencedor foi o que implementava um período de aprendizagem após a abolição da escravidão. Nele, os ex-escravos deveriam trabalhar parte da semana para seus antigos senhores como devolução das provisões de comida, vestimenta, habitação e cuidados médicos, e, na outra parte do tempo, deveriam trabalhar por salário, para os mesmos antigos senhores ou outros proprietários (Holt, 1992, p. 48).

Holt apontou que os formuladores do sistema de aprendizagem "viam os escravos como crianças a serem reeducadas como trabalhadores assalariados e ressocializados como cidadãos" (Holt, 1992, p. 56). Magistrados especiais ficariam responsáveis pelo papel de reforçar a disciplina do trabalho, antes atribuído aos senhores, sendo que as punições iam de multa por meio de trabalho extra, encarceramento e açoitamento. Para o autor, os escravos das Índias Ocidentais

seriam livres, mas somente após serem ressocializados para aceitar a disciplina interna que assegurasse a sobrevivência da ordem social existente. Eles seriam livres para barganhar no mercado, mas não livres para ignorá-lo. Eles seriam livres para perseguirem seus interesses próprios, mas não livres para rejeitar o condicionamento cultural que definia quais eram os próprios interesses (Holt, 1992, p. 53).

Verifica-se, portanto, que tanto no Brasil quanto no Império Português, no contexto da abolição, circulavam ideias semelhantes sobre o controle dos egressos do cativeiro, em diálogo com outras experiências, como a do Império 
Britânico, mencionada anteriormente. Nesse sentido reforçava-se a imagem de que a tendência "natural" dos negros à ociosidade justificaria uma transição gradual à liberdade. Embora a associação entre o negro e a indolência seja uma marca do processo de diferenciação racial no contexto da abolição nesses espaços, existiam explicações diferentes, que ora apontavam para características biológicas, ora para aspectos exteriores, como o clima e a fertilidade do solo. Além disso, apesar de predominante, não era um discurso uníssono, e havia contestações à própria ideia de uma indolência atávica aos negros, como a formulada por Sá da Bandeira, apesar de o mesmo ainda considerá-los numa escala inferior da civilização.

É importante frisar-se ainda que, ao contrário do apontado tanto por parte da historiografia brasileira quanto da portuguesa ${ }^{10}$, essas não são construções de sentidos que podem ser entendidas unicamente dentro das fronteiras nacionais, mas que se formaram justamente pelo intenso diálogo que transpassava esses limites e eram forjadas, inclusive, com referência a várias experiências internacionais abolicionistas.

A associação entre a ociosidade e os negros se relacionava, nos discursos do contexto abolicionista, à adoção do trabalho coercitivo como um caminho a ser adotado. Zamparoni, ao comentar sobre Moçambique, apontou que:

a fé pretensamente natural e universal de que o trabalho e a acumulação de seus frutos eram a base de toda a vida individual e social, faziam crer que aos civilizadores era imposta a tarefa de arrancar o indígena deste estado natural de indolência e ociosidade e submetê-lo a uma disciplina do trabalho, alterando a sua conduta diante do mesmo (Zamparoni, 2012, pp. 34-35).

Nesse sentido, tanto no Brasil quanto no Império Português, baseados em exemplos internacionais, foi criada a ideia de que a compulsoriedade do trabalho dos libertos seria atingida, por um lado, por uma maior regulação dos contratos de trabalho, e, por outro, pelo recrudescimento da repressão a da vadiagem.

\section{REGULA-SE O TRABALHO, REPRIME-SE A VADIAGEM}

Em Portugal, a demanda dos proprietários pela regulação do trabalho e pelo controle da vadiagem dos egressos do cativeiro teve uma resposta em 
1875. Nesse ano, uma lei proposta por Sá da Bandeira apontava que, em 1876, os indivíduos iriam da condição de libertos para livres, ficando, os mesmos, sujeitos à tutela pública e obrigados a contratar seus serviços por dois anos, de preferência com os antigos patrões (Lei de 29 de abril de 1875). A ideia da tutela estava presente, por exemplo, na fala do ministro da marinha Mendes Leal, como visto anteriormente e, no parecer da Comissão que apreciou a referida lei, indicava-se que o objetivo da mesma era justamente proteger os "menores e os assimilados a estes", ou seja, os negros. Segundo o parecer, “a experiência das diferentes nações coloniais tem, desde séculos, mostrado os mil modos que se tem abusado da ignorância e desvalimento da classe trabalhadora nas colônias". Nesses lugares, a escravidão teria apenas mudado de nome e foi resultado da "liberdade absoluta nas condições de contratar quem nem lhe conhecia o valor, nem talvez se percebia de a possuir". A tutela do Estado surgia, portanto, como uma forma de impedir os egressos do cativeiro "de renunciarem aos benefícios da liberdade antes de terem contraído os seus hábitos" (Câmara dos Pares do Reino, Seção de 31 de março de 1874). Dentro dessa visão, ao Estado caberia, portanto, civilizar os negros através do trabalho compulsório e, com isso, protegê-los das armadilhas da liberdade repentina.

A referida Comissão apontou também que a "vadiagem em semelhantes períodos de transição é o primeiro e mais pernicioso vício a prevenir, e implantado, difícil, senão impossível será extirpá-lo”. Mencionava ainda que, diante da necessidade de obrigar a trabalhar aqueles que tiveram a condição servil abolida, era necessário que se "estabeleçam cuidadosamente as bases fundamentais dos contratos para trabalho" (Câmara dos Pares do Reino, Seção de 31 de março de 1874).

Ainda em 1875, foi implementado um regulamento que especificava ainda mais a questão dos contratos de prestação de serviço ${ }^{11}$. Esses contratos poderiam estipular apenas o salário, ou o salário, o sustento e o vestuário, e teriam prazo de cinco anos - ou dez, no caso de aprendizes. Estabelecia-se ainda o teto de nove horas e meia de trabalho, e folga aos domingos, bem como as penas em razão de falta injustificada. Os salários mínimos, assim como o "mínimo de ração", seriam determinados nos regulamentos específicos de cada província. Além disso, a ausência do trabalho durante quinze dias seguidos "sem motivo será considerada como vadiagem, e como tal sujeita às penas" estabelecidas no próprio regulamento (Regulamento para execução da lei...). 
No que diz respeito ainda à vadiagem, o documento indicava que os indivíduos tornados livres pela lei, e sob a tutela pública, seriam julgados enquanto tais seguindo as condições do artigo 256 do Código Penal Português (Regulamento para execução da lei...). Este determinava que era vadio quem não tinha "domicílio certo em que habite, nem meios de subsistência, nem exercita habitualmente alguma profissão ou ofício, ou outro mister em que ganhe a vida”. A punição era a prisão correcional por seis meses, e o culpado seria "entregue à disposição do governo, para lhe fornecer trabalho pelo tempo que parecer conveniente" (Código Penal aprovado..., 1855).

O Regulamento de 1875 determinou pena bem mais rigorosa para os africanos, já que os julgados como vadios estariam "sujeitos a trabalho obrigatório até dois anos nos estabelecimentos do estado, que para isso fossem especialmente criados, ou nas fortalezas e obras públicas da província, e receberão o salário que for estabelecido pelo respectivo governador". Abria-se ainda a possibilidade de que os condenados contratassem "em qualquer tempo os seus serviços com pessoas particulares, e nesse caso cessa a obrigação do serviço público" (Regulamento para execução da lei...). Garantia-se, assim, o suprimento de mão-de-obra para os patrões locais. Ainda era considerado como vadiagem, no referido regulamento, a perturbação, ou mesmo a tentativa de perturbação, nos estabelecimentos dos patrões, ou ainda o aliciamento dos empregados para abandonarem tais estabelecimentos.

Em 1878, quando cessaria esse período de transição, o governo português expediu um novo regulamento para os contratos de trabalho, reeditando, em grande medida, o regulamento anterior ${ }^{12}$. A justificativa presente no próprio documento era de que "o estado dos indígenas não os habilita ainda a promoverem, por si próprios, a manutenção dos seus direitos de cidadãos livres, e que, por tal razão, uma proteção especial da autoridade se lhes torna essencial" (Regulamento para os contratos de serviçais..., 1878).

É importante ressaltar a utilização do termo indígena pelo regulamento como referência aos africanos negros. Se literalmente significava "os nascidos no país”, naquele contexto, segundo Isabel Castro Henrique, o termo adquiria "uma funcionalidade pejorativa que desqualifica e serve para designar aquele que por essa razão está condenado ao trabalho obrigatório" (Henriques, 2004, p. 294). A mesma autora afirmou que essa construção se deu por uma operação de reelaboração da representação do africano, cujo objetivo era colocar "em 
evidência o caráter congênito da selvageria". Segundo ela, "a própria selvageria da imagem serve para justificar a imposição de uma ferocíssima disciplina do trabalho" (Henriques, 2004, pp. 287-288). Os regulamentos de 1875 e 1878 respondiam, assim, à demanda da classe patronal pela necessidade de maior regulação dos contratos e, ao mesmo tempo, de controle sobre a vadiagem.

No caso brasileiro, mesmo após a lei de 1871, a demanda por regulação dos contratos e perseguição à vadiagem prosseguiu. Os Congressos Agrícolas, que reuniram fazendeiros em Recife e no Rio de Janeiro no ano de 1878, são importantes espaços para perceber os clamores da classe senhorial ${ }^{13}$. No Congresso de Recife, o engenheiro francês Henrique Millet, que morava em Pernambuco, expunha a urgência de uma "boa lei de locação de serviços, que regule também os direitos e obrigações recíprocas do senhor de engenho e do lavrador ou morador" (Trabalhos do Congresso Agrícola..., 1978, p. 315 apud Dantas; Costa, 2016). Já Joaquim Alvares dos Santos Souza afirmava a necessidade de "reformar as leis de locação de serviços, tornando-as mais garantidoras dos contratos, que serão escritos pelas partes contratantes, criando penas e multas para os indivíduos que a violarem". Acrescentava ainda a importância da criação de "leis repressivas da vagabundagem, que obriguem todo cidadão sem arte, ofício ou emprego, a procurar trabalho" (Trabalhos do Congresso Agrícola..., 1978, p. 401 apud Dantas; Costa, 2016).

Peter Eisenberg, ao analisar o Congresso Agrícola ocorrido no Rio de Janeiro no mesmo ano, apontou que, embora a ociosidade do trabalhador nacional fosse ponto pacífico entre os congressistas, havia discordância sobre as causas e curas. Havia quem "identificava a ociosidade como resultado da falta de repressão" e demandava "uma maior repressão da vagabundagem, 'uma boa lei de locação de serviços' e 'sumaríssimo processo'” (Eisenberg, 1989, p. 145). Nesse grupo, se encontrava, por exemplo, o lavrador Joaquim Eduardo Brandão, do município mineiro de Mar de Hespanha, que instava o governo a tomar providências para acabar com a vadiagem. Nos povoados do interior, segundo ele, "em cada porta de venda, encontram-se quatro, cinco, seis e mais libertos ou emancipados, que não querem trabalhar", tendo o governo, portanto, a necessidade de promover uma medida policial ou correcional "que os obrigue a prestarem-se ao serviço da lavoura". Afirmava ainda que o mesmo deveria ser aplicado às mulheres, "que são alforriadas e vão para os cortiços entregar-se à vadiação, ao vício": é "preciso corrigi-las, obrigá-las ao 
trabalho" (Congresso Agrícola do Rio..., 1988, p. 182). Observa-se uma distinção de gênero nas definições de vadiagem semelhante à encontrada por Lerice Garzoni num período um pouco posterior. Assim sendo, enquanto para os homens a atribuição da vadiagem estava predominantemente relacionada ao trabalho, para as mulheres ela resvalava também por aspectos morais, sendo geralmente direcionada ao seu comportamento sexual (Garzoni, 2007).

Já a representação dos lavradores de Baependi apontava que a comunidade social não poderia e não deveria "permitir que uma parte de seus membros continue em estado de barbárie, e menos ainda que outra parte que, sem possuir fortuna ou rendimentos próprios, come, bebe e veste, isto é, consome gêneros produzidos pelo trabalho, viva na ociosidade". Apelava também para que, "a par das leis repressivas da ociosidade, se promulgue logo uma boa lei de locação de serviços, que garanta a execução dos contratos dos fazendeiros com os operários", pois na atual situação as desvantagens estavam do lado dos fazendeiros (Congresso Agrícola do Rio..., 1988, p. 58).

Existia também, segundo Eisenberg, os que culpavam os próprios fazendeiros, com a justificativa de "que os grandes proprietários abrigavam homens livres improdutivos, nas suas propriedades, para fins eleitorais" (Eisenberg, 1989, p. 145). Por fim, estava o grupo que acreditava faltarem estímulos positivos que incentivassem a saída da ociosidade.

No que diz respeito à reivindicação pela reforma da regulamentação dos contratos de trabalho, essa teve como resposta o decreto de 1879, que ampliava o controle sobre os contratos de locação de serviços ${ }^{14}$. O documento estabelecia que a duração dos contratos seria de seis anos, caso o locador fosse brasileiro, ou cinco, se fosse estrangeiro. No caso dos libertos, seguia-se a determinação da Lei de 1871. A ausência do trabalho, sem justa causa, passou a ser punida, naquele momento, com pena de cinco a 20 dias de prisão. Além disso, principiou-se a prescrição de punições para os locadores que se recusassem a trabalhar, os quais eram submetidos à mesma pena mencionada anteriormente. Já os trabalhadores envolvidos nas paralisações, que cometessem ameaças ou violências, recebiam penas específicas (Decreto n. 2.827, de 15 de março de 1879).

A maior repressão à vadiagem, por sua vez, veio com a lei aprovada em 28 de setembro de 1885, conhecida como "Lei dos Sexagenários”. Essa tinha como um dos principais pontos a libertação dos escravos maiores de 60 anos. 
No entanto, havia a condição de que eles trabalhassem por mais três anos para seus antigos senhores, como forma de indenização pela alforria. Estava previsto também que os escravos alforriados pelo Fundo de Emancipação seriam obrigados a permanecer no município em que receberam a alforria pelo período de cinco anos. Os que se ausentassem de seu domicílio seriam considerados vagabundos e apreendidos pela Polícia, para serem empregados "em trabalhos públicos ou colônias agrícolas”. Além disso, o liberto encontrado sem ocupação seria "obrigado a empregar-se ou a contratar seus serviços no prazo que lhe for marcado pela Polícia”. Terminado o prazo, se o liberto não cumprisse a determinação da Polícia, ele seria enviado ao Juiz de Órfãos, "que o constrangerá a celebrar contrato de locação de serviços, sob pena de 15 dias de prisão com trabalho e de ser enviado para alguma colônia agrícola no caso de reincidência" (Lei de 28 de setembro de 1885). A punição à vadiagem se tornava ainda mais complexa e especificada que na lei de 1871 , e intentava principalmente imobilizar o liberto no município em que ele trabalhava, sob a alçada do poder de seu antigo senhor, bem como estipulava o prazo da prisão para os libertos encontrados sem ocupação.

$\mathrm{O}$ processo de abolição português foi trazido à tona no debate sobre a referida "Lei dos Sexagenários". Na seção de 8 de agosto de 1885, da Câmara dos Deputados, Leopoldo Bulhões indicou que, em 1856, Portugal votou a libertação do ventre e, em 1858, a medida radical de dar o prazo de 20 anos para o fim da escravidão. O deputado mencionou ainda que Sá da Bandeira propôs, em 1874, “a abolição imediata com a condição de serviços" (Diários da Câmara dos Deputados, Seção de oito de agosto de 1885).

O mesmo Leopoldo Bulhões havia apresentado, na sessão de nove de julho de 1885, um projeto de lei, juntamente com outros deputados, em que propunham a extinção da escravidão, porém, indicavam que os libertos estariam obrigados a prestar serviço "aos seus ex-senhores pelo prazo de cinco anos”. O projeto previa, ainda, o salário mínimo dos libertos, bem como a obrigação de que recebessem o vestuário, a alimentação e o tratamento das enfermidades (Diários da Câmara dos Deputados, Seção de 9 de julho de 1885). O projeto parece ser inspirado na legislação portuguesa, particularmente no regulamento de trabalho de 1878 , mas acabou não tendo o mesmo sucesso e não foi aprovado.

As tentativas de solucionar a questão do controle sobre os trabalhadores 
libertos, no entanto, não foram suficientes, e, em 1888, alguns dias antes da assinatura da lei que libertava todos os escravizados e as escravizadas, a princesa Isabel ressaltava a importância do fim da escravidão, mas também de aperfeiçoar a "nossa legislação repressiva da ociosidade". Ainda naquele ano, logo após a referida lei, se iniciou uma nova discussão sobre a repressão à vadiagem, como expôs Sidney Chalhoub (1983).

\section{CONSIDERAÇÕES FINAIS}

No que diz respeito à formulação de políticas de controle sobre o trabalhador liberto no período da abolição, procurou-se indicar as possíveis aproximações entre o Brasil e o Império Português. Nesse sentido, em ambas as localidades apontava-se para a necessidade de medidas repressivas que obrigassem os libertos a trabalhar, fosse através de contratos de trabalho mais rígidos, fosse pela repressão à vadiagem. Apesar das semelhanças, as trajetórias dos locais possuem também as suas próprias especificidades.

As políticas anti-vadiagem, no entanto, eram comuns a outros contextos abolicionistas. Em Cuba, segundo Christian G. De Vito, entre 1881 e 1889 ocorreu um amplo debate sobre a vadiagem, o qual "tratava de projetar medidas legais que permitissem imobilizar na plantation a força de trabalho anteriormente escravizada". Essas medidas variavam do "alistamento compulsório no exército de todos os negros entre dezoito e vinte e oito anos", ao estabelecimento de casas de correção. De Vito sugeriu que a repressão à vadiagem é um "exemplo da adaptabilidade da punição à mudança das relações sociais e trabalhistas e a diferentes contextos espaciais". O autor argumentou que as políticas mudaram à medida que a "conceptualização da vadiagem (vagancia) evoluiu para atingir diferentes grupos e atingir objetivos distintos" (De Vito, 2018). Segundo ele, as políticas anti-vadiagem "assumem o centro do palco como uma ferramenta punitiva altamente dinâmica para controlar as populações urbanas e rurais, e como uma forma de expulsar e imobilizar grupos sociais distintos", antes e depois da abolição (De Vito, 2018).

Já Alessandro Stanziani mostrou que, no Império Britânico e no Império Francês - na Índia, no Oceano Índico e na África -, a abolição oficial da escravidão "foi seguida por regras extremamente coercitivas a respeito de vadios, emitidas em nome da ordem pública e crescimento econômico como um an- 
tídoto para a pobreza". A política anti-vadiagem nesses espaços foi um exemplo, para o autor, de que, mesmo após o fim da escravidão, a linha divisória entre a liberdade e a falta dela não era clara no mundo do trabalho, que "continuou a ser um mundo de exploração desigual e às vezes de extrema violência" (Stanziani, 2018).

O Brasil estava, portanto, inserido em um contexto global de abolição da escravidão, que colocava a perseguição à vadiagem no palco principal. Sendo assim, na legislação abolicionista brasileira, assim como na de vários outros lugares, a punição à vadiagem garantiria, segundo a classe senhorial da época, a possibilidade de manter os trabalhadores egressos do cativeiro, impedindo que eles abandonassem as localidades em que trabalhavam, bem como imputando a obrigatoriedade de que eles trabalhassem para algum patrão.

A perseguição à vadiagem não era algo novo em nenhum dos espaços mencionados ao longo do texto - Brasil e Império Português, mais especificamente -, mas, no processo de abolição, ganhou outros contornos. Nesse contexto, a definição de quem era vadio ou vadia, no caso do Brasil e do Império Português, foi permeada pelos marcadores raciais, sendo atribuída aos negros e às negras uma natural ociosidade e a rejeição ao trabalho. Dessa forma, classe e raça se intersecionam, no sentido de que, dentro de uma prática que já criminalizava as classes subalternas, foi criada uma nova diferenciação, que desvelava um aumento na repressão e no controle justamente sobre os homens e as mulheres de pele negra. As representações de gênero também impactaram, embora com menos força, na documentação aqui compulsada, as formulações do que significava ser vadio ou vadia.

A reelaboração da representação do trabalhador negro liberto foi o grande manancial que serviu para justificar o papel civilizador dos brancos, ao imputar o trabalho como um dever compulsório a essa parcela da população e, relacionado a isso, para embasar o recrudescimento da ação repressiva aos temidos vadios e vadias. $\mathrm{O}$ negro e a negra atavicamente indolentes não estavam preparados, de acordo com essa representação, para uma liberdade repentina, e a coerção ao trabalho era o único meio de educá-los.

Essa representação foi eficaz, entre outras coisas, porque foi construída na inter-relação entre vários contextos abolicionistas. No entanto, havia também vozes dissonantes. Como exposto no início do presente artigo, poucos dias antes da assinatura da abolição no Brasil, o jornal Gazeta da Tarde con- 
testava a ideia do governo de que o liberto seria necessariamente inimigo da ordem pública e do trabalho, e questionava se a real intenção era "libertar os negros para metê-los na cadeia” (Semana parlamentar, 1888, p. 1).

Se a historiografia do trabalho no Brasil deu um grande passo ao não se limitar à análise do trabalho assalariado e também incluir trabalhadoras e trabalhadores escravizados, é importante ainda avançar na análise dos efeitos do racismo no processo da formação da classe trabalhadora brasileira (Nascimento, 2016). O presente texto pretendeu ser uma contribuição nesse sentido, ao analisar como, no contexto global da abolição, foram forjadas, no Brasil e no Império Português, representações e práticas repressivas que relacionavam trabalho, ociosidade e racismo.

\section{REFERÊNCIAS}

ALENCASTRO, Luiz Felipe de. Proletários e escravos: imigrantes portugueses e cativos africanos no Rio de Janeiro, 1850-1872. Novos Estudos, n. 21, pp. 30-56, 1988.

ANAIS DO IMPÉRIO (digitalizados) (1823-1888). Disponível em: https://www.senado.leg.br/publicacoes/anais/asp/IP_AnaisImperio_digitalizados.asp. Acesso em: 21 mar. 2021.

ARANTES, Erika Bastos. O Porto Negro: trabalho, cultura e associativismo dos trabalhadores portuários no Rio de Janeiro na virada do XIX para o XX. Tese (Doutorado em História) - Instituto de Ciências Humanas e Filosofia, Universidade Federal Fluminense. Niterói, 2010. $223 \mathrm{f}$.

BANDEIRA, Marquês de Sá da. O trabalho rural africano e a administração colonial. Lisboa: Imprensa Nacional, 1873.

BEM, Gabriel Felipe Silva. Raça e colonização: noções raciais no discurso colonial de Sá da Bandeira e Andrade Corvo em Portugal (1873-1887). Dissertação (Mestrado em História) - Departamento de História, Universidade Federal de Minas Gerais. Belo Horizonte, 2020.

BRASIL. Jornal do Commercio, Rio de Janeiro, 7 jan. 1872, p. 2.

BRASIL. Código Criminal do Império do Brasil anotado (1830) pelo Juiz de Direito Antonio Luiz Ferreira Tinoco. Rio de Janeiro: Imprensa Industrial, 1886.

CÂMARA DOS PARES DO REINO (1842-1910). Disponível em: https://debates.parlamento.pt/catalogo/mc/cp2. Acesso em: 10 mar. 2021.

CÂMARA DOS SENHORES DEPUTADOS da Nação Portuguesa (1822-1910). Disponível em: https://debates.parlamento.pt/catalogo/mc/cd. Acesso em: 10 mar. 2021. 
CHALHOUB, Sidney. Vadios e barões no ocaso do Império: o debate sobre a repressão da ociosidade na Câmara dos Deputados em 1888. Estudos Ibero-Americanos, v. 9, n. 1-2, pp. 53-67, 1983.

CHALHOUB, Sidney. Visões da liberdade: uma história das últimas décadas da escravidão na corte. São Paulo. Companhia das Letras, 1990.

CÓDIGO PENAL APROVADO por Decreto de 10 de dezembro de 1852. Lisboa: Imprensa Nacional, 1855.

CONGRESSO AGRÍCOLA DO RIO de Janeiro, 1878. Anais. Rio de Janeiro: Fundação Casa de Rui Barbosa, 1988.

CRAVO, Télio Anísio; RODRIGUES, Pedro Conterno; GODOY, Marcelo Magalhães. Imigração internacional e contratos de trabalho no Império do Brasil: colonos europeus na construção de estradas na década de 1830. Almanack, v. 25, pp. 1-34, 2020.

DANTAS, Monica Duarte; COSTA, Vivian Chieregati. O "pomposo nome de liberdade do cidadão": tentativas de arregimentação e coerção da mão-de-obra livre no Império do Brasil. Estudos Avançados, v. 30, n. 87, pp. 29-48, 2016.

DIÁRIOS DA CÂMARA DOS DEPUTADOS a partir de 16 de novembro de 1890. Disponível em: https://imagem.camara.leg.br/diarios.asp?selCodColecaoCsv=D. Acesso em: 14 abr. 2021.

DUVERNAY-BOLENS, Jacqueline. L'homme zoologique. Races et racisme chez les naturalistes de la première moitié du XIX ${ }^{e}$ siècle. L'Homme, v. 35, n. 133, pp. 9-32, 1995.

EISENBERG, Peter L. O homem esquecido: o trabalhador livre nacional no século XIX: sugestões para uma pesquisa. In: Homens esquecidos: escravos e trabalhadores livres no Brasil, séculos XVIII e XIX. Campinas, Unicamp, 1989. pp. 223-245.

O ELEMENTO SERVIL XI. Diário do Rio de Janeiro, Rio de Janeiro, 16 abr. 1871, p. 2.

EMANCIPAÇÃO: RESUMO DA SEMANA. Jornal do Commercio, Rio de Janeiro, 2 jul. 1871, p. 5.

ESPÍNDOLA-SOUZA, Mayza. A liberdade do contrato: o trabalho africano na legislação do Império Português, 1850-1910. Dissertação (Mestrado em História) - Centro de Filosofia e Ciências Humanas, Universidade Federal de Santa Catarina. Florianópolis, 2017.

GARZONI, Lerice de Castro. Vagabundas e conhecidas: novos olhares sobre a polícia republicana (Rio de Janeiro, início de século XX). Dissertação (Mestrado em História) - Instituto de Filosofia e Ciências Humanas, Universidade de Campinas. Campinas, 2007.

GIAROLA, Flávio Raimundo. Trabalho e combate à vadiagem: representações da mãode-obra nos discursos dos periódicos de São João del-Rei (1871-1888). Temporalidades, v. 4, n. 1, pp. 278-302, 2012. 
HOLLOWAY, Thomas H. Doing Favors for Street People: Official Responses to Beggars and Vagrants in Nineteenth-Century Rio de Janeiro. In: BEIER, A. L.; OCOBOCK, Paul (Orgs.). Cast Out: Vagrancy and Homelessness in Global and Historical Perspective. Athens: Ohio University Press, 2008. pp. 162-183.

HOLT, Thomas C. The Problem of Freedom: Race, Labor, and Politics in Jamaica and Britain, 1832-1938. Baltimore: Johns Hopkins University Press, 1992.

KOWARICK, Lúcio. Trabalho e Vadiagem: a origem do trabalho livre no Brasil. Rio de Janeiro: Paz e Terra, 1994.

LAMOUNIER, Maria Lucia. Formas da transição da escravidão ao trabalho livre: a Lei de Locação de Serviços de 1879. Dissertação (Mestrado em História) -Instituto de Filosofia e Ciências Humanas, Universidade de Campinas. Campinas, 1986.

LEI DE 11 DE OUTUBRO DE 1837. Disponível em: http://legis.senado.leg.br/norma/541072/publicacao/15632760 Acesso em: 8 abr. 2021.

LEI DE 28 DE SETEMBRO DE 1871. Disponível em: http://www.planalto.gov.br/ccivil_03/leis/lim/lim2040.htm Acesso em: 10 mar. 2021.

LEI DE 28 DE SETEMBRO DE 1885. Disponível em: http://www.planalto.gov.br/ ccivil_03/leis/lim/LIM3270.htm Acesso em: 5 abr. 2021.

LEI DE 29 DE ABRIL DE 1875. Disponível em: https://www.fd.unl.pt/Anexos/Investigacao/1425.pdf Acesso em: 14 mar. 2021.

LIMA, Henrique Espada. Sob o domínio da precariedade: escravidão e os significados da liberdade de trabalho no século XIX. Topoi, v. 6, n. 11, pp. 289-326, 2005.

LINDEN, Marcel van der. Trabalhadores do mundo: ensaios para uma História Global do Trabalho. Campinas: Editora da Unicamp, 2013.

MARQUES, João Pedro. Sá da Bandeira e o fim da escravidão: Vitória da moral, desforra do interesse. Lisboa: Imprensa de Ciências Sociais, 2008.

MARTINEZ, Esmeralda Simões. O trabalho forçado na legislação colonial portuguesa: o caso de Moçambique (1899-1926). Dissertação (Mestrado em História) - Faculdade de Letras, Universidade de Lisboa. Lisboa, 2008.

MARTINS, Joaquim Pedro de Oliveira. O Brasil e as Colónias Portuguesas. Lisboa: Livraria Bertrand, 1880.

MATTOS, Marcelo Badaró. Vadios, jogadores, mendigos e bêbados na cidade do Rio de Janeiro do início do século. Dissertação (Mestrado em História) - Programa de Pós-Graduação em História, Universidade Federal Fluminense. Niterói, 1991.

MENDONÇA, Joseli Maria Nunes. Leis para "os que se irão buscar" - imigrantes e relações de trabalho no século XIX brasileiro. História: Questões e Debates, n. 56, pp. 63-85, 2012.

MEYER, Felix. O trabalho livre em Angola e o estado desta província. Lisboa: Typografia Progresso, 1874. 
NASCIMENTO, Álvaro Pereira. Trabalhadores negros e o "paradigma da ausência": contribuições à história social do trabalho no Brasil. Estudos Históricos, v. 29, n. 59, pp. 607-626, 2016.

PINTO, Ana Flávia Magalhães. A Gazeta da Tarde e as peculiaridades do abolicionismo de Ferreira de Menezes e José do Patrocínio. In: SIMPÓSIO NACIONAL DE HISTÓRIA, XXVIII, 2015, Florianópolis. Anais do XXVIII Simpósio Nacional de História. Florianópolis: Anpuh, 2015. pp. 1-17.

PIRES, Alfredo de Oliveira. Algumas reflexões sobre a questão do trabalho nas possessões portuguesas d'África. Lisboa: Typografia Progresso, 1874.

POPINIGIS, Fabiane; TERRA, Paulo Cruz. Classe, raça e a história social do trabalho no Brasil (2001-2016). Estudos Históricos, Rio de Janeiro, v. 32, n. 66, pp. 307-328, 2019.

REGULAMENTO PARA EXECUÇÃO DA LEI de 29 de Abril de 1875. Disponível em: https://www2.ifch.unicamp.br/cecult/lex/web/uploads/da927b9b0aa93e489c21965e78286b6f922c070d.pdf. Acesso em: 14 mar. 2021.

REGULAMENTO PARA OS CONTRATOS DE SERVIÇAIS e colonos nas províncias da África Portuguesa, 1878. Disponível em: https://www.fd.unl.pt/Anexos/Investigacao/1426.pdf. Acesso em: 4 mar. 2021.

SEMANA PARLAMENTAR. Gazeta da Tarde, 7 mai. 1888, p. 1.

STANZIANI, Alessandro. Labor on the Fringes of Empire: Voice, Exit and the Law. London: Palgrave Macmillan, 2018.

TRABALHOS DO CONGRESSO AGRÍCOLA do Recife. Edição fac-similar comemorativa do primeiro centenário,1878-1978. Recife: Cepa-PE, 1978.

DE VITO, Christian G. History without Scale: the Micro-Spatial Perspective. Past \& Present, v. 242, pp. 348-372, 2019.

DE VITO, Christian G. Punishment and Labour Relations. Cuba between Abolition and Empire (1835-1886). Crime, Histoire \& Sociétés/Crime, History \& Societies, v. 22, n. 1, pp. 53-79, 2018.

WINN, Peter. Global Labor History: The Future of the Field? International Labor and Working-Class History, n. 82, pp. 85-91, 2012.

YOUSSEF, Alain El. O Império do Brasil na segunda era da abolição, 1861-1880. Tese (Doutorado em História) - Faculdade de Filosofia, Letras e Ciências Humanas, Universidade de São Paulo. São Paulo, 2019.

ZAMPARONI, Valdemir Donizette. De escravo a cozinheiro: colonialismo \& racismo em Moçambique. Salvador: EDUFBA/CEAO, 2012. 


\section{NOTAS}

${ }^{1}$ Professor do Departamento de História e do Programa de Pós-Graduação em História da Universidade Federal Fluminense. Bolsista de Produtividade em Pesquisa do CNPq e Jovem Cientista do Nosso Estado da FAPERJ. O presente artigo apresenta resultados preliminares de pesquisa que contou com financiamento da CAPES e da Alexander von Humboldt Foundation.

${ }^{2}$ Toda a grafia das citações foi atualizada, embora tenha se mantido, dos originais, a pontuação e a utilização das letras maiúsculas.

${ }^{3}$ Sobre a relação entre a Gazeta da Tarde e o abolicionismo, ver Pinto (2015).

${ }^{4}$ São várias as análises que se debruçaram sobre a questão da vadiagem na Primeira República. Alguns exemplos, no caso do recorte no Rio de Janeiro, são Mattos (1991); Garzoni (2007); Arantes (2010).

${ }^{5}$ Ver, por exemplo: Espada (2005); Mendonça (2012); Dantas e Costa (2016); Cravo, Rodrigues e Godoy, 2020.

${ }^{6}$ O texto de Henrique Espada Lima (2005) é uma importante exceção ao abordar esse aspecto.

${ }^{7}$ Flávio Giarola (2012), ao analisar as representações da vadiagem nos periódicos de São João del-Rei, no período de 1871 a 1888, encontrou formulações muito semelhante às apresentadas aqui.

${ }^{8}$ Sobre as ideias raciais e racistas de Geoffroy Saint-Hilaire, ver Duvernay-Bolens (1995).

${ }^{9}$ Sobre a trajetória de Sá da Bandeira, ver: Marques (2008). Mais especificamente sobre a questão racial presente no discurso de Sá da Bandeira, verificar Bem (2020).

${ }^{10}$ No que diz respeito às análises que se concentram somente no Império Português, ver, por exemplo, Esmeralda (2008). No caso brasileiro, ver Kowarick (1994).

${ }^{11}$ Uma análise mais aprofundada sobre o referido Regulamento é possível se encontrar em Maysa Espíndola-Souza (2017).

${ }^{12}$ Esmeralda Martinez (2008) aborda de forma mais detalhada o Regulamento de 1878.

${ }^{13}$ Sobre o Congresso Agrícola de Recife, ver: Dantas e Costa (2016).

${ }^{14}$ Sobre a Lei de Locação de Serviços de 1879, uma importante análise foi feita por Maria Lucia Lamounier (1986).

Artigo submetido em 28 de abril de 2021 . Aprovado em 30 de junho de 2021. 